\title{
Behavior of Asynergic Ventricle
}

\author{
Yoshiro Nakamura, M.D., Masando Takahashi, M.D., \\ and Shigehiko HatTori, M.D.
}

\begin{abstract}
SUMMARY
Effect of increased left atrial pressure and a positive inotropic agent upon asynergic left ventricle which was produced by acute occlusion of LAD were examined in 8 open-chest dogs. Systolic bulging in ischemic area was qualified by ESL/EDL in percentage. Left atrial pressure was controlled by the reservoir connected to left atrial appendage with a large bore tubing. Cardiac output and aortic pressure were decreased following coronary occlusion without change in isometric developed tension in nonischemic area of left ventricle. Increase of left atrial pressure from $5 \mathrm{mmHg}$ to $14 \mathrm{mmHg}$ produced rise in stroke volume to $191 \%$ and rise in aortic pressure to $156 \%$ in asynergic left ventricle respectively. These increases were not accompanied by change in ESL/EDL.

Therefore, extracardiac factors were assumed to explain the prominent increase in left ventricular stroke work by elevation of left atrial pressure in asynergic left ventricle. Isoproterenol enhanced total cardiac performance by increasing the function of nonischemic area without deterious effect on the ischemic area.
\end{abstract}

\section{Additional Indexing Words:}

Coronary occlusion Systolic bulge Segment length Isometric tension Preload Isoproterenol

CINCE Tennant and Wiggers") showed that acute occlusion of coronary $D$ artery produced systolic bulging of the ischemic myocardium in 1935, sequestration of the blood into the systolic bulge has been believed to be at least one of the main causes of deterioration of left ventricular function by acute myocardial infarction. The time dependent improvement of ventricular function following acute episode of myocardial infarction has been demonstrated relating to change in ventricular compliance by several investigators, ${ }^{2), 3)}$ however, the relationship between contractility of uninvolved myocardium and mechanical behavior of ischemic myocardium has not been clear. An understanding of the effects of various therapeutic approaches designed to improve ventricular function on ischemic myocardium could have clinical

From the Department of Internal Medicine, School of Medicine, Keio University and Nomura Medical Center of Health Care.

Address for reprint request: Yoshiro Nakamura, M.D., Department of Internal Medicine, Keio University, 35 Shinanomachi, Shinjuku, Tokyo 160, Japan.

Received for publication February 28, 1977. 
importance. The purpose of the present study is to reveal the effects of increased left atrial pressure and positive inotropic agent upon asynergic left ventricle.

\section{METHOD}

Eight mongrel dogs weighing $15-20 \mathrm{Kg}$ were anesthetized with sodium pentobarbital in an initial dose of $30-40 \mathrm{mg} / \mathrm{Kg}$. Thoracotomy was performed in the fifth left intercostal space under the artificial respiration by a Havard pump. The left anterior coronary artery (LAD) was dissected about $4 \mathrm{~cm}$ below the bifurcation of the main segment for the passage of a ligature around the vessel. Aortic blood flow was measured with a squarewave electromagnetic flowmeter. Ascending aortic blood pressure was measured through a catheter. Left ventricular pressure was measured through a short polyethylene cannula which was inserted into the left ventricular cavity via apex and attached directly to a pressure transducer. The first derivative of left ventricular pressure $(\mathrm{dp} / \mathrm{dt}$ ) was obtained electrically. A reservoir filled with normal saline was connected to the left atrial appendage with a large bore tubing in order to keep left atrial pressure constant during each experimental procedure. Left atrial pressure was measured through a catheter. Left ventricular segment length was measured by the use of prongs which measured displacement through a strain gauge. Segment length measurements were made adjacent to LAD in the direction perpendicular to the course of LAD. Local isometric force of the left ventricle was measured by the use of small-sized strain gauge arch. The arch was sutured to the superficial layer of the myocardium in the direction parallel to the left circumflex coronary artery $(\mathrm{CX})$, with streching the

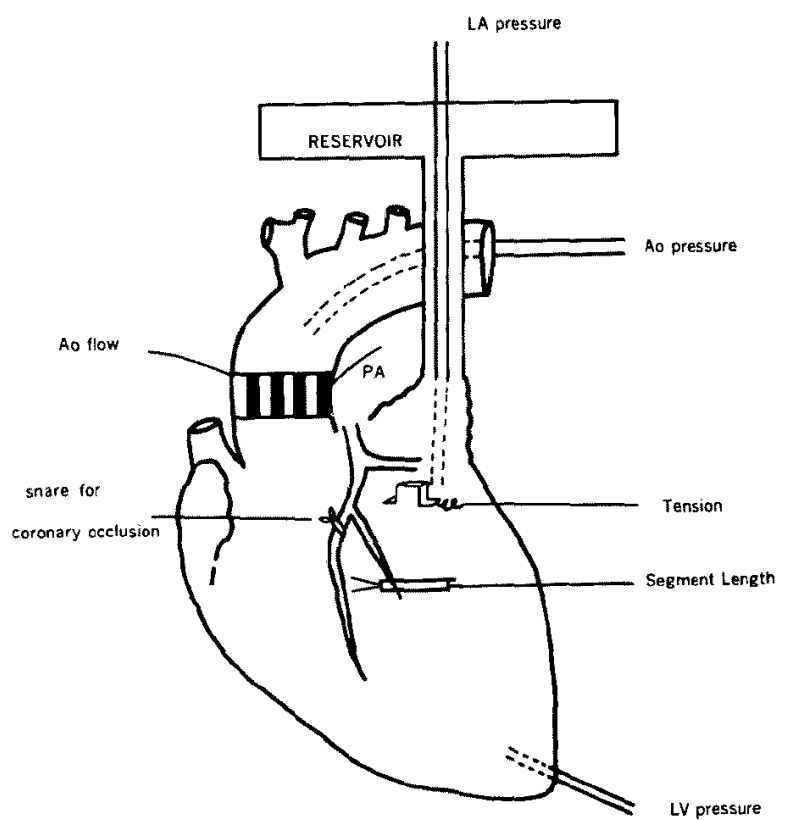

Fig. 1. Schema of the presentation.

Ao: Aorta, LV: left ventricle, LA : left atrium, PA: pulmonic artery. 
resting muscle length by approximately $20 \%$ (Fig. 1). Transient occlusion of LAD artery produced grossly ischemic myocardium which was supplied by this vessel. We chose this area for the suturing site for prongs, and reconfirmed by repeated transient occlusion. The rest of the myocardium of the free wall of left ventricle was confirmed non-involved by this maneuver, and the strain gauge was applied.

Effects of increased left atrial pressure from about $5 \mathrm{mmHg}$ to $14 \mathrm{mmHg}$ on left ventricular function were examined in control state and $3 \mathrm{~min}$ after occlusion of LAD. On asynergic left ventricle, effect of a positive inotropic agent was tested by continuous infusion of isoproterenol intravenously. Data were recorded when heart rate was increased up to $115 \%$ of control state at left atrial pressure of about $5 \mathrm{mmHg}$ and $14 \mathrm{mmHg}$ respectively.

Regional myocardial function of non-ischemic arca was represented by isometric developed tension. When left atrial pressure was changed in each experimental maneuver, tension measured by strain gauge arch could be modified by the change in tension of sourrounding myocardium, ${ }^{4)-6)}$ therefore, isometric developed tension should be evaluated in comparison with data taken at the same left atrial pressure. Systolic bulging in ischemic area was quantified by end-systolic length/end-diastolic segment length (ESL/EDL) in percentage. End-diastolic pressure-length relationship was shown as following calculation ?):

$$
\mathrm{K}=\frac{\Delta \mathrm{P}}{\Delta \mathrm{L} / \mathrm{EDL}_{5} \times 100} \mathrm{mmHg} \text { in } \Delta \mathrm{EDL}
$$

where $\mathrm{K}=$ slope of the pressure-length relationship. $\Delta \mathrm{P}=$ changes in left atrial pressure (from about $5 \mathrm{mmHg}$ to $14 \mathrm{mmHg}$ ). $\quad \Delta \mathrm{L}=$ changes in $\mathrm{EDL}$. $\mathrm{EDL}_{5}=$ EDL at left atrial pressure of about $5 \mathrm{mmHg}$.

\section{Result}

Effect of increase in lcft atrial pressure on intact and regionally ischemic left ventricle:

Table I. Effect of Occlusion of LAD on Intact Ventricle

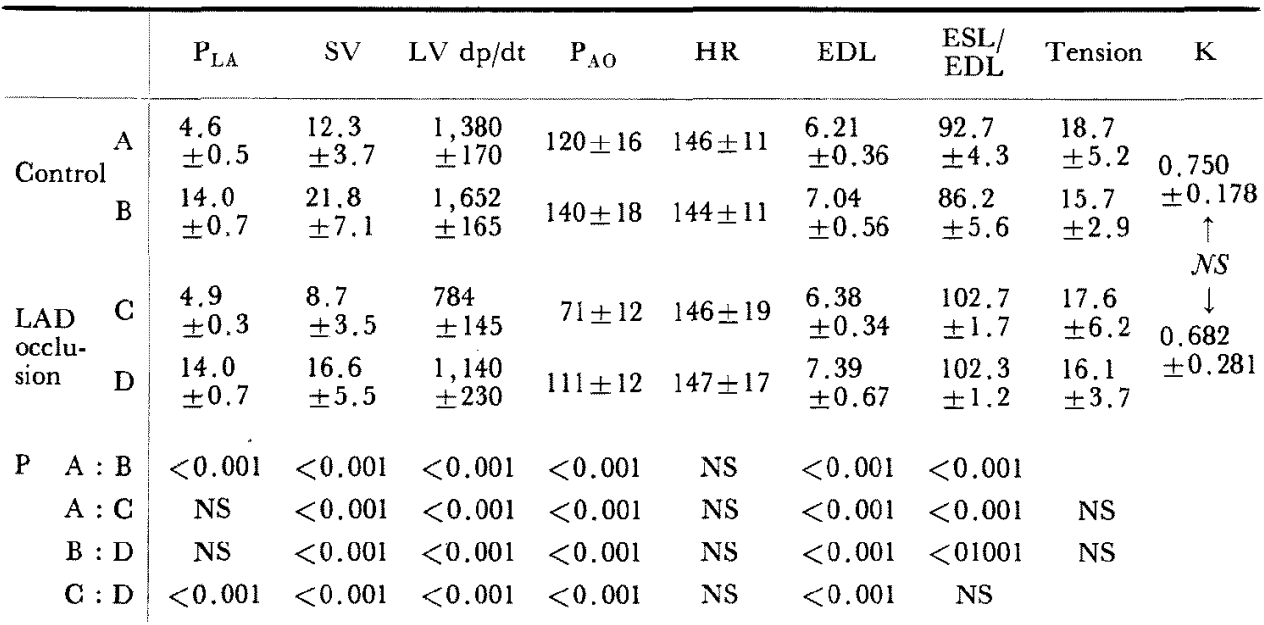


Table I showed changes in hemodynamic parameters of the left ventricle produced by occlusion of LAD at $5 \mathrm{mmHg}$ and $14 \mathrm{mmHg}$ of left atrial pressure. In intact left ventricle, EDL was streched to $113 \%$ in mean value, stroke volume was increased to $177 \%$ and aortic pressure was elevated to $117 \%$ of control value by increase in left atrial pressure from $4.6 \mathrm{mmHg}$ to $14 \mathrm{mmHg}$. After occlusion of LAD, aortic pressure, maximum $\mathrm{LV} \mathrm{dp} / \mathrm{dt}$ and stroke volume were dropped markedly without the change in heart rate, and isometric developed tension in uninvolved area were unchanged. In ischemic area, EDL were prolonged slightly but significantly by $2.8 \%$ and $4.9 \%$ at left atrial pressure of $4.9 \mathrm{mmHg}$ and $14 \mathrm{mmHg}$ respectively. Nevertheless stiffness of the left ventricular wall in ischemic area presented by $\mathrm{K}$ decreased in 4 cases and increased in 4 cases. Systolic bulging in ischemic
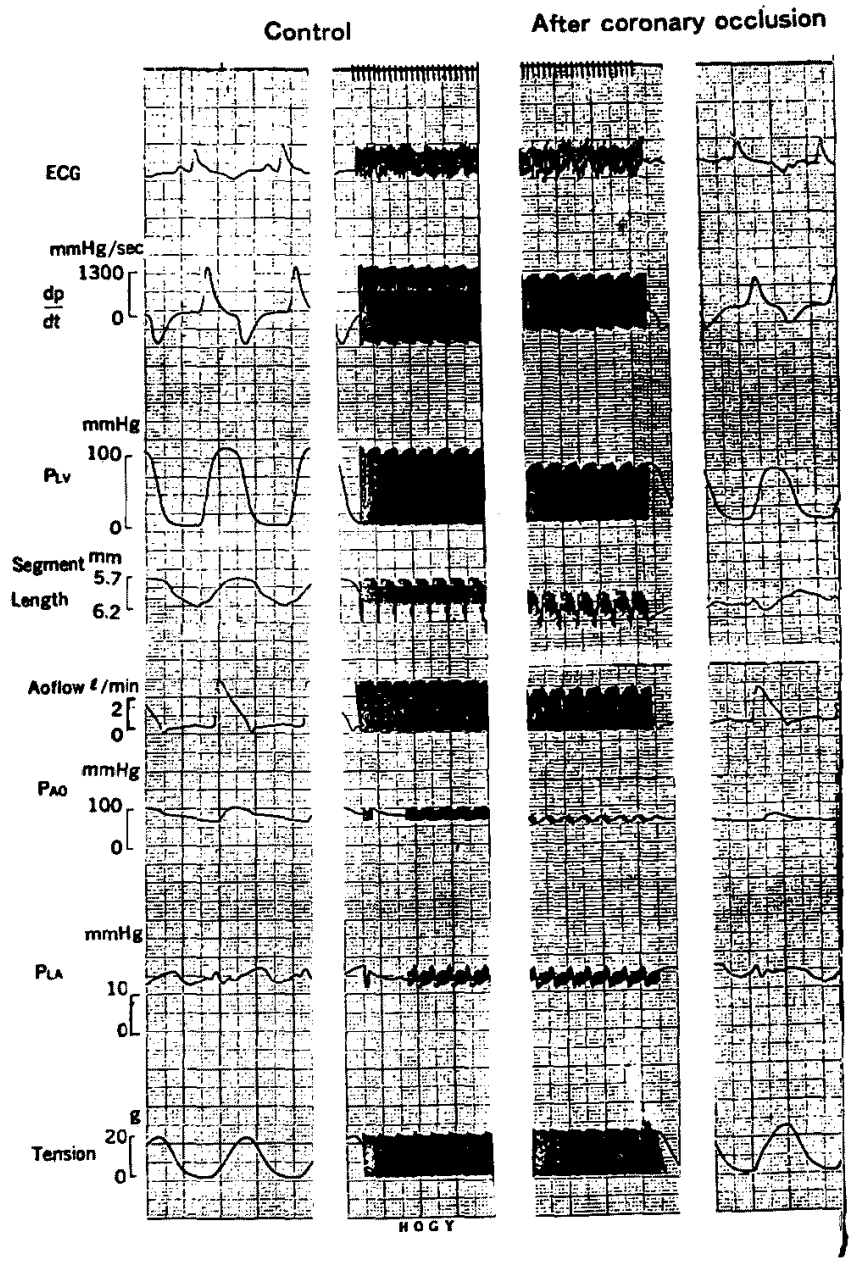

Fig. 2. The representative recordings of hemodynamics following occlusion of LAD. 
area was completed within $1 \mathrm{~min}$ after coronary occlusion (Fig. 2). This systolic lengthening of the ischemic myocardium was unchanged and ESL/EDL was also unchanged statistically by increase in left atrial pressure. Increase of left atrial pressure produced rise in stroke volume to $191 \%$ and rise in aortic pressure to $156 \%$ in asynergic left ventricle.

Effect of isoproterenol on asynergic left ventricle (Table II):

Infusion of isoproterenol which increased heart rate up to $115 \%$ resulted in increase of stroke volume, but did not change aortic pressure at both levels of atrial pressure. Therefore, this increment of stroke volume was due to increase in contractility which was shown by increase in isometric developed tension of uninvolved myocardium. Isoproterenol did not change ESL/EDL in ischemic myocardium and stiffness of the ischemic left ventricular wall (K), while shortening of EDL of ischemic area occurred slightly but significantly. Effect of increased left atrial pressure on stroke work in asynergic left ventricle during infusion of isoproterenol was more prominent than that in normal ventricle.

\section{Discussion}

The changes in local myocardial function following coronary occlusion have been studied by many investigators, ${ }^{4)-10)}$ employing a variety of techniques. In the use of the strain gauge arch to measure the local forces in the ischemic left ventricular wall, it was pointed out that the indirect effect of the sorrounding normal tissue on the gauge could importantly affect the measurement

Table II. Effect of Isoproterenol on Asynergic Ventricle

\begin{tabular}{|c|c|c|c|c|c|c|c|c|c|c|}
\hline & & $\mathrm{P}_{\mathrm{LA}}$ & SV & $\begin{array}{l}\mathrm{LV} \\
\mathrm{dp} / \mathrm{dt}\end{array}$ & $P_{A O}$ & HR & EDL & $\begin{array}{l}\text { ESL/ } \\
\text { EDL }\end{array}$ & Tension & $\mathbf{K}$ \\
\hline \multirow{2}{*}{\multicolumn{2}{|c|}{$\begin{array}{l}\text { LAD } \\
\text { occlusion } \\
D\end{array}$}} & $\begin{array}{l}4.9 \\
\pm 0.3\end{array}$ & $\begin{array}{l}8.7 \\
\pm 3.5\end{array}$ & $\begin{array}{l}784 \\
\pm 145\end{array}$ & $71 \pm 12$ & $146 \pm 19$ & $\begin{array}{l}6.38 \\
\pm 0.34\end{array}$ & $\begin{array}{l}102.7 \\
\pm 1.7\end{array}$ & $\begin{array}{l}17.6 \\
\pm 6.2\end{array}$ & \multirow{2}{*}{$\begin{array}{c}0.682 \\
\pm 0.281 \\
\uparrow \\
\text { NS }\end{array}$} \\
\hline & & $\begin{array}{l}14.0 \\
\pm 0.7\end{array}$ & $\begin{array}{l}16.6 \\
\pm 5.5\end{array}$ & $\begin{array}{r}1,140 \\
\pm 230\end{array}$ & $111 \pm 12$ & $147 \pm 17$ & $\begin{array}{l}7.39 \\
\pm 0.67\end{array}$ & $\begin{array}{l}102.3 \\
\pm 1.2\end{array}$ & $\begin{array}{l}16.1 \\
\pm 3.7\end{array}$ & \\
\hline \multirow{2}{*}{\multicolumn{2}{|c|}{$\begin{array}{l}\text { LAD } \\
\text { occlusion E } \\
\text { with } \\
\text { Isoprote- F } \\
\text { renol }\end{array}$}} & $\begin{array}{l}4.8 \\
\pm 0.6\end{array}$ & $\begin{array}{l}10.8 \\
\pm 3.4\end{array}$ & $\begin{array}{r}1,030 \\
\pm 265\end{array}$ & $73 \pm 12$ & $170 \pm 10$ & $\begin{array}{l}6.15 \\
\pm 0.30\end{array}$ & $\begin{array}{l}103.7 \\
\pm 2.1\end{array}$ & $\begin{array}{l}21.4 \\
\pm 6.7\end{array}$ & \multirow{6}{*}{$\begin{array}{c}\downarrow \\
0.635 \\
\pm 0.283\end{array}$} \\
\hline & & $\begin{array}{l}13.9 \\
\pm 0.6\end{array}$ & $\begin{array}{l}21.5 \\
\pm 5.7\end{array}$ & $\begin{array}{r}1,562 \\
\pm 191\end{array}$ & $113 \pm 9$ & $173 \pm 5$ & $\begin{array}{l}7.21 \\
\pm 0.68\end{array}$ & $\begin{array}{l}102.9 \\
\pm 1.3\end{array}$ & $\begin{array}{l}22.6 \\
\pm 4.9\end{array}$ & \\
\hline \multirow[t]{4}{*}{$\mathbf{P}$} & $\mathrm{C}: \mathrm{D}$ & $<0.001$ & $<0.001$ & $<0.001$ & $<0.001$ & NS & $<0.001$ & NS & & \\
\hline & $\mathrm{C}: \mathrm{E}$ & NS & $<0.001$ & $<0.001$ & NS & $<0.001$ & $<0.01$ & NS & $<0.001$ & \\
\hline & $\mathrm{D}: \mathbf{F}$ & NS & $<0.001$ & $<0.001$ & NS & $<0.001$ & $<0.05$ & NS & $<0,001$ & \\
\hline & $\mathbf{E}: \mathbf{F}$ & $<0.001$ & $<0.001$ & $<01001$ & $<0.001$ & NS & $<0.001$ & NS & & \\
\hline
\end{tabular}


of force within an ischemic area. ${ }^{4-6)}$ When bulging of the ischemic myocardium is the object of investigation, segmental lengthening of the ischemic myocardium should be recorded. Almost all studies used a mercury-in-silastic tubing gauge for measuring segmental length of the myocardium. ${ }^{7-9)}$ We have published previously the effect of change in afterload upon ischemic bulge in comparison to left ventricular hemodynamics and have emphasized the importance of pressure-length relationship in ischemic myocardium. ${ }^{22}$ ) Many investigators discussed the characteristics of the ischemic regional myocardium by the method of pressure-length loop. ${ }^{81,11,13)}$

The contractile characteristics of non-ischemic myocardium after coronary occlusion have not been clear, because so many factors affected the contractility. Wyatt et al $^{14)}$ revealed that depression of left ventricular function after coronary occlusion might be partially related to depression of function in apparently " non-ischemic" myocardium by analysing the systolic shortening of the regional myocardium against left ventricular end-diastolic pressure which was controlled arbitrarily. In this experiment, we minimized the change of left ventricular volume by which measurement of isometric developed tension was affected and showed no significant change in non-ischemic myocardial contraction after coronary occlusion.

But we could not conclude that depression of left ventricular function after coronary occlusion was only due to loss of contractility and systolic bulging in ischemic myocardium. The effect of increase in preload on stroke work after coronary occlusion was more prominent than that in control state, and the paradoxical expansion of the ischemic myocardium was not increased by elevation of left atrial pressure after coronary occlusion. Moreover, isometric developed tension in the nonischemic myocardium was not altered by coronary occlusion. These results suggested that extracardiac factors -c.g. systemic vascular resistance and circulatory blood volume have played important roles in this situation.

Puri and Bing ${ }^{15}$ have represented that the ischemic zone showed an increase in the amplitude of paradoxical systolic expansion, although the nonischemic myocardium responded to drugs like norepinephrine, metaraminol and isoproterenol in a normal manner. Our previous study could show an increase in the amplitude of systolic bulge in ischemic muscle by increment of afterload, ${ }^{12)}$ but in the present study, neither an increase in preload, nor an administration of isoproterenol could produced an increase in the amplitude of systolic bulge.

Therefore, we concluded that isoproterenol enhanced total cardiac performance by increasing the function of non-ischemic area without deterious effects on the ischemic area, when aortic pressure was not increased significantly. 


\section{References}

1. Tennant $\mathrm{R}$, Wiggers $\mathrm{CJ}$ : The effect of coronary occlusion on myocardial contraction. Am J Physiol 112: 351, 1935

2. Hood WB Jr, Bianco JA, Kumar R, Whiting RB: Experimental myocardial infarction IV. Reduction of left ventricular compliance in the healing phase. J Clin Invest 49: 1316, 1970

3. Forrester JS, Diamond G, Parmley WW, Swan HJC: Early increase in left ventricular compliance after myocardial infarction. J Clin Invest 51: 598, 1972

4. Newman WH, Walton RP: Strain gauge arch recording from an acutely ischemic area of left ventricle. J Appl Physiol 23: 398, 1967

5. Newman WH, Walton RP: Alterations in left ventricular dimensions and mural force following coronary occlusion. Am J Physiol 214: 1388, 1968

6. Yoshida S: Experimental studies of coronary insufficiency. I. Ghanges in myocardial contractility in the ischemic area of the ventricle following acute coronary occlusion. Jap Circulat J 33: 1253, 1969

7. Pirzada FA, Ekong EA, Vokonas PS, Apstein CS, Hood WB Jr: Experimental myocardial infarction XIII. Sequential changes in left ventricular pressure-length relationships in the acute phase. Circulation 53: 970,1976

8. Tyberg JV, Forrester JS, Wyatt HL et al: An analysis of segmental ischemic dysfunction utilizing the pressure-length loop. Circulation 53: 970, 1974

9. Banka VS, Helfant RH: Temporary sequence of dynamic contractile characteristics in ischemic and nonischemic myocardium after acute coronary ligation. Am J Cardiol 34: 158, 1974

10. Theroux P, Ross J Jr, Franklin D et al: Regional function during acute coronary artery occlusion and its modification by pharmacologic agents in the dog. Circulat Res 35: 896, 1974

11. Theroux P, Ross J Jr, Franklin D et al: Regional myocardial function in the conscious dog during acute coronary occlusion and responses to morphine, propranolol, nitroglycerin and lidocaine. Circulation 53: 302, 1976

12. Nakamura $\mathrm{Y}$, Nagoshi $\mathrm{H}$, Takei $\mathrm{F}$ et al: The inhomogenous movement of the left ventricle induced by coronary artery occlusion. Jap Heart J 13: 150, 1972

13. Forrester JS, Tyberg JV, Wyatt HL et al: Pressure-length loop. A new method for simultaneous measurement of segmental and total cardiac function. J Appl Physiol 37: 771, 1974

14. Wyatt HL, Forrester JS, LaLuz PL et al: Functional abnormalities in nonoccluded regions of myocardium after experimental coronary occlusion. Am J Cardiol 37: 366, 1976

15. Puri PS, Bing RJ: Effect of drugs on myocardial contractility in the intact dog in experimental myocardial infarction. Am J Cardiol 21: 886, 1968 